\title{
Tryptophan-sorbitol based carbon quantum dots for theranostics against hepatocellular carcinoma
}

Yang Wang ${ }^{1,2,3+}$, Jun Chen ${ }^{1,3,4+}$, Jiekang Tian ${ }^{5+}$, Guanchen Wang ${ }^{5}$, Weikang Luo ${ }^{2,3}$, Zebing Huang ${ }^{1,3,4}$, Yan Huang ${ }^{1,3,4}$, Ning Li $i^{1,3,6^{*}}$, Mingming Gu $0^{5^{*}}$ and Xuegong Fan ${ }^{1,3,4^{*}}$ (D)

\begin{abstract}
Background: Despite novel advances in screening, targeting and immunotherapies, early diagnosis and satisfactory treatments against hepatocellular carcinoma (HCC) remain formidable challenges. Given the unique advantages, carbon quantum dots (CQDs) become a smart theranostic nanomaterial for cancer diagnosis and therapy.

Results: In this work, a type of bio-friendly CQDs, trichrome-tryptophan-sorbitol CQDs (TC-WS-CQDs), is synthesized from natural biocompatible tryptophan via the one-pot hydrothermal method. Compared with normal hepatocytes, a much stronger green fluorescence is detected in HCC cells, indicating the ability of TC-WS-CQDs to target HCC cells. Furthermore, green-emitting TC-WS-CQDs generate large amounts of reactive oxygen species (ROS), leading to autophagy of HCC cells. Additionally, the green-emitting TC-WS-CQDs perform significant tumor inhibition by inducing autophagy via p53-AMPK pathway in vitro and in vivo studies with almost no systemic toxicity.
\end{abstract}

Conclusions: The results may highlight a promising anticancer nanotheranostic strategy with integration of diagnosis, targeting, and therapy.

Keywords: Tryptophan, Sorbitol, Carbon quantum dots, Theranostics, Hepatocellular carcinoma

\footnotetext{
*Correspondence: liningxy@csu.edu.cn; guomm57@swu.edu.cn; xgfan@hotmail.com

†Yang Wang, Jun Chen and Jiekang Tian contributed to this work equally

1 Key Laboratory of Viral Hepatitis of Hunan Province, Xiangya

Hospital, Central South University, Xiangya Road 87, Kaifu District,

Changsha 410008, China

${ }^{5}$ School of Chemistry and Chemical Engineering, Southwest University,

Tiansheng Road, Beibei District, Chongaing 400715, China

Full list of author information is available at the end of the article
}

(c) The Author(s) 2022. Open Access This article is licensed under a Creative Commons Attribution 4.0 International License, which permits use, sharing, adaptation, distribution and reproduction in any medium or format, as long as you give appropriate credit to the original author(s) and the source, provide a link to the Creative Commons licence, and indicate if changes were made. The images or other third party material in this article are included in the article's Creative Commons licence, unless indicated otherwise in a credit line to the material. If material is not included in the article's Creative Commons licence and your intended use is not permitted by statutory regulation or exceeds the permitted use, you will need to obtain permission directly from the copyright holder. To view a copy of this licence, visit http://creativecommons.org/licenses/by/4.0/. The Creative Commons Public Domain Dedication waiver (http://creativeco mmons.org/publicdomain/zero/1.0/) applies to the data made available in this article, unless otherwise stated in a credit line to the data. 


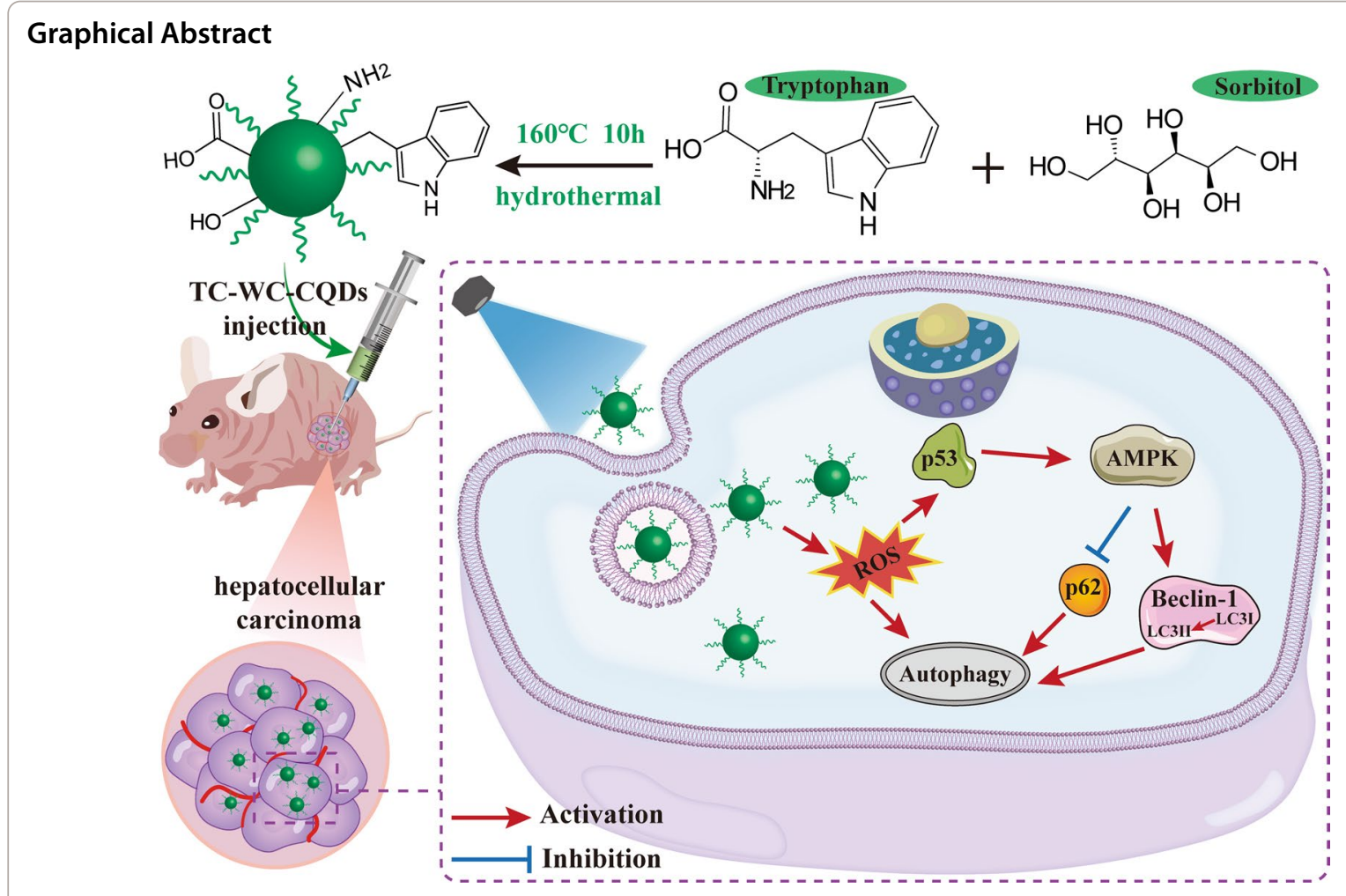

\section{Introduction}

Liver cancer is the sixth ranked cancer, as well as the third leading cause of cancer death worldwide in 2020, with approximately 906,000 new cases and 830,000 deaths [1]. Among all types of liver cancer, hepatocellular carcinoma (HCC) accounts for $75-85 \%$ of the total cases [1]. Despite novel advances in screening, targeting and immunotherapies, early diagnosis and satisfactory treatments remain formidable challenges [2]. The overall mortality is up to $95 \%$ because of the low percentage of radical resectable HCC on diagnosis [3]. Although liver transplantation tends to be an optimal treatment, critical shortage of available liver allografts limits the application [4]. Even the new-generation drugs merely make the median overall survival continue to be 1 year [5]. Current randomized trials of immune checkpoint inhibitor therapy, such as anti-programmed cell death protein 1 (antiPD-1) and anti-programmed cell death-ligand protein 1 (anti-PD-L1) monotherapy, do not demonstrate significant improvement in overall survival against HCC [6]. More potential screening tests and efficacious therapies to prolong mean survival are extremely urgent [4].

Considering limitations of standard diagnosis and therapeutics, we realize that the dominant "one-sizefits-all" diagnostic and therapeutic agents for cancer treatment have heralded the need for "personalized medicine" [7]. Personalized medicine aims to maximize therapeutic efficacy with minimal delay after diagnosis [8]. To achieve this goal, theranostics is focused, which offers promising prospects in personalized medicine. Theranostics is a single platform to combine diagnosis and therapy, not only provides precise information on position, type and size of tumors, but also functions as preferable therapeutics [9]. Thus, theranostics has emerged as a hot spot research in cancer treatment [10].

With frontier developments of nanotechnology in medical field [11-13], scientists are striving to explore nanotheranostic strategy for HCC prevention [14]. To improve theranostic efficiency, lots of drug delivery nanosystems have been developed [15-17]. Of these functionalized nanomaterials, carbon quantum dots (CQDs) attract great research attention due to their unique advantages, including ultrasmall size, high water-solubility, excellent photoluminescence (PL), broad emission range and outstanding biocompatibility [18, 19]. Additionally, CQDs, as a class of zero-dimensional carbon nanomaterials, contain many functional groups such as epoxy, carbonyl, hydroxyl, amine, and carboxyl on their surfaces and/or edges, which give rise to high hydrophilicity and readiness for functionalization with biological species [20, 21]. Given these properties, CQDs become a 


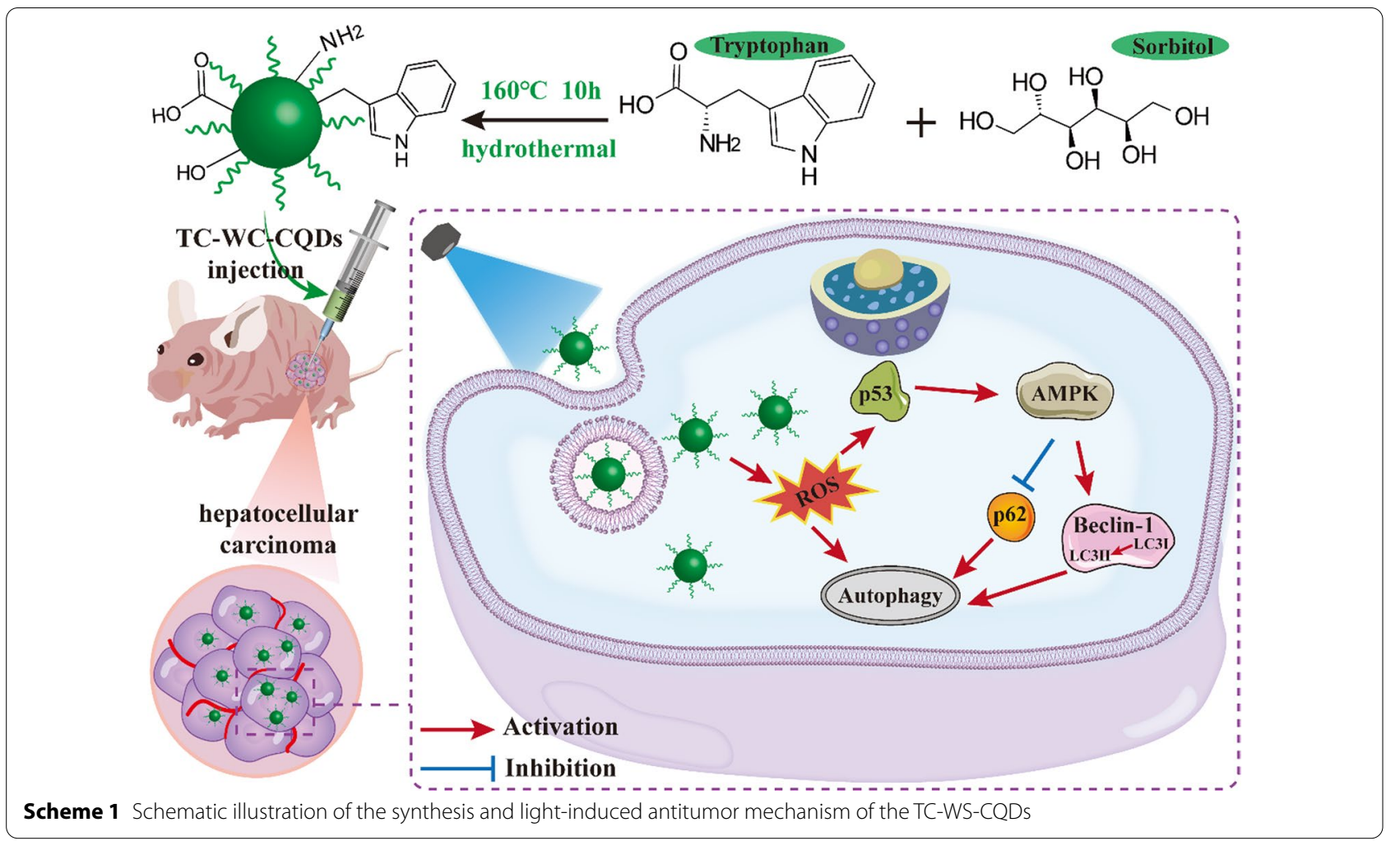

smart theranostic nanomaterial to exhibit tumor identification and enhance anticancer effects.

There have been numerous studies on exploration of CQDs for cancer diagnosis and therapy [22-24]. However, most of these studies focused on either fluorescent diagnosis or anticancer activity, few concentrated on the intrinsic theranostic applications [19]. Moreover, CQDs may irradiate with light degrade into molecules that are toxic to both normal and malignant cells [25]. Therefore, it is imperative to design synthetic CQDs for theranostics using natural carbon sources as precursors without organic solvents.

Herein, we fabricate hybrid fluorescent trichrometryptophan-sorbitol CQDs (TC-WS-CQDs) from natural biocompatible tryptophan via a green hydrothermal method. The formed CQDs $(\sim 1.4 \mathrm{~nm})$ include conjugated structure induced by tryptophan and scaffold structure formed by sorbitol, which exhibit three-color emission (blue, green, and red). Compared with normal hepatocytes, we found that TC-WS-CQDs were more willing to be selectively delivered into HCC cells by endocytosis. The TC-WS-CQDs exhibited strong visible blue, green and red fluorescence in tumor cells under different excitation wavelengths. Furthermore, we found that green-emitting TC-WS-CQDs generated large amounts of reactive oxygen species (ROS), leading to autophagy of HCC cells. In addition, these green-emitting
TC-WS-CQDs performed significant tumor inhibition by inducing autophagy via p53-AMPK pathway in vitro and in vivo studies with almost no systemic toxicity. The results may highlight a promising anticancer nanotheranostic strategy with integration of diagnosis, targeting, and therapy (Scheme 1).

\section{Methods \\ Materials}

Tryptophan and 2,2,6,6-tetramethylpiperidine were purchased from Sigma-Aldrich (St.Louis, MO, USA). Sorbitol was supplied by Aladdin Biochemical Technology Co., Ltd (Shanghai, China). Dulbecco's Modified Eagle's Medium (DMEM, high glucose), Roswell Park Memorial Institute (RPMI) 1640 medium, and 10\% fetal bovine serum (FBS) were purchased from Naer Biotechnology Co., Ltd (Tianjin, China). LysoTracker Red was obtained from Maokang Biotechnology Co., Ltd (Shanghai, China). Cell Counting Kit-8 (CCK8) was obtained from Vazyme Biotech Co., Ltd (Nanjing, China). The 3-(4,5-dimethylthiazol-2-yl)-5-(3-carboxymethoxyphenyl)-2-(4-sulfophenyl)-2H-tetrazolium, inner salt (MTS) was obtained from Promega Corporation (USA). Reactive Oxygen Species Assay Kit was supplied by Beyotime (Shanghai, China). Nystatin, Chlorpromazine, $N$-acetylcysteine (NAC) and Apocynin (APO) were obtained from Selleck. cn (Shanghai, China). mCherry-GFP-LC3 fusion protein 
were purchased from Tsingke Biotechnology Co., Ltd (Beijing, China).

\section{Synthesis of TC-WS-CQDs}

Tryptophan (100 mg, $0.49 \mathrm{mmol}$ ) and sorbitol (500 mg, $2.74 \mathrm{mmol}$ ) were dissolved in water and diluted to $50 \mathrm{ml}$, and the mixture was divided into ampoules of $5 \mathrm{ml}$ capacity, which was sealed and heated to $160{ }^{\circ} \mathrm{C}$ for $10 \mathrm{~h}$. After cooling to room temperature, the ampoules were stored at $4{ }^{\circ} \mathrm{C}$ for future use.

\section{Synthesis of blue (B), green (G) and red (R)-WS-CQDs}

TC-WS-CQDs $(100 \mathrm{ml})$ were centrifuged at $8000 \mathrm{~g}$ for $10 \mathrm{~min}$ and the supernatant was lyophilized. The lyophilized powder was purified by silica-gel column chromatography gradient elution, starting from ethyl acetate: ethanol $=10: 1$, and gradually increasing the polarity of the eluent to ethyl acetate: ethanol $=1: 1$. Depending on the separation effect, the silica-gel column chromatography process may need to be repeated two or more times to obtain the blue (B), green (G) and red (R)-WS-CQDs.

\section{Cellular imaging and transmission electron microscopy}

In the cell image experiments, the hepatoma cells (Huh7 cells) were seeded into 24-well plates with cell climbing slice and cultured overnight. Then, cells were incubated with TC-WS-CQDs $(100 \mu \mathrm{g} / \mathrm{ml})$ for $6 \mathrm{~h}$. Next, cells were washed with phosphate buffered saline (PBS) three times and fixed with $4 \%$ paraformaldehyde for $15 \mathrm{~min}$. After that, images were acquired with a laser scanning confocal microscopy (LSCM) under the excitation wavelengths of $405 \mathrm{~nm}, 488 \mathrm{~nm}$, and $545 \mathrm{~nm}$. For the transmission electron microscopy (TEM) analysis, after incubation with TC-WS-CQDs for $6 \mathrm{~h}$, trypsinized Huh7 cells were fixed with 3\% glutaraldehyde in phosphate-buffered saline and then were sent to the Department of Pathology in Xiangya Hospital for further processing and scanning.

\section{Lyso-Tracker Red staining}

Lysosomal staining was performed using Lyso-Tracker Red (Invitrogen, L7528). Huh7 cells were seeded into 24-well plate with cell climbing slice. After $6 \mathrm{~h}$ of treatment with TC-WS-CQDs $(100 \mu \mathrm{g} / \mathrm{ml})$, cells were incubated with LysoTracker Red at $75 \mathrm{nM}$ for $30 \mathrm{~min}$ at $37^{\circ} \mathrm{C}$ and washed three times with PBS. Then, cells were fixed with $4 \%$ paraformaldehyde and photographed with fluorescence microscope under the excitation wavelength of $545 \mathrm{~nm}$.

\section{Cytotoxicity assay}

Cell viability was estimated by CCK8 and MTS assay. Huh7 cells and the normal liver cells (L02 cells) were seeded into 96 -well plates at a density of $8 \times 10^{3}$ cells/well overnight, followed by incubation with TC-WS-CQDs with different concentrations $(0,50,100,200 \mu \mathrm{g} / \mathrm{ml})$. The media with non-cells was blank control. After incubation with different time (12 h, $24 \mathrm{~h}, 48 \mathrm{~h}), 10 \mu \mathrm{l}$ CCK8 (Vazyme, A311-02) or $20 \mu \mathrm{l}$ MTS (Promega, G3582) solution were added to each well for $2 \mathrm{~h}$. Finally, the optical density (OD) of the wells was measured at $450 \mathrm{~nm}$ (CCK8) and $490 \mathrm{~nm}$ (MTS) by a microplate reader. Based on the OD value, cell viability was calculated: cell viability $(\%)=\left(\mathrm{OD}_{\text {treated }}-\mathrm{OD}_{\text {blank }}\right) /\left(\mathrm{OD}_{\text {control }}-\mathrm{OD}_{\text {blank }}\right) \times 100 \%$ $\left(\mathrm{OD}_{\text {control }}, \mathrm{OD}_{\text {treated }}\right.$ and $\mathrm{OD}_{\text {blank }}$ were the values obtained without or with TC-WS-CQDs and blank control, respectively).

\section{Antitumor effects of TC-WS-CQDs in vitro Proliferation assay}

In the cell proliferation experiments, Huh7 cell suspensions with TC-WS-CQDs $(75 \mu \mathrm{g} / \mathrm{ml})$ or without TCWS-CQDs were continuously exposed to or not exposed to light (470 nm or $545 \mathrm{~nm}$ ) equipped with fluorescence microscope for $10 \mathrm{~min}$. After different treatment, $100 \mu \mathrm{l}$ cell suspensions were transferred to 96 -well plates $\left(5 \times 10^{3}\right.$ cells/well), and $10 \mu \mathrm{l} \mathrm{CCK} 8$ or $20 \mu \mathrm{l}$ MTS solution was added to each well after culturing for $0 \mathrm{~h}, 24 \mathrm{~h}$, $48 \mathrm{~h}, 72 \mathrm{~h}$ and $96 \mathrm{~h}$. Following incubation for another $2 \mathrm{~h}$, the OD value was assessed as previously described in cytotoxicity assay.

\section{Wound healing assay}

Cell migration capacity was measured by wound healing assay. $\sim 4 \times 10^{5} \mathrm{Huh} 7$ cells with different treatment were seeded into 6-well plates and cultured in DMEM with $10 \%$ FBS. After cells reached $90-100 \%$ confluence, a line wound was scratched by a $10 \mu \mathrm{l}$ tip and the detached cells were removed by washing with PBS. Subsequently, the cells were cultured in serum-free DMEM. The wounds were observed at $0 \mathrm{~h}, 24 \mathrm{~h}, 48 \mathrm{~h}$ and $72 \mathrm{~h}$. The wound healing rate was calculated according to the following formula: Wound healing rate $=[$ (wound width at $0 \mathrm{~h})-$ (wound width at each time point)]/(wound width at $0 \mathrm{~h}) \times 100 \%$.

\section{Reactive oxygen species and singlet oxygen measurement}

Intracellular production of ROS was determined using Reactive Oxygen Species Assay Kit (Beyotime, S0033). After $24 \mathrm{~h}$ incubation with different treatment, cells were incubated with $10 \mu \mathrm{M} \mathrm{2}$ ',7'-dichlorodihydrofluorescein diacetate dye (DCFH-DA) in DMEM for $30 \mathrm{~min}$. Then, cells were washed with PBS, trypsinized and resuspended in PBS. The green fluorescence (DCFH-DA), corresponding to ROS levels, was determined using flow cytometer, microplate reader and fluorescence microscope. 
$\mathrm{N}$-acetylcysteine (Selleck, S1623) and Apocynin (Selleck, S2425) were used as ROS inhibitors in this research.

For the singlet oxygen $\left({ }^{1} \mathrm{O}_{2}\right)$ detection, three samples of TC-WS-CQDs aqueous solution containing 1\% 2,2,6,6-tetramethylpiperidine (TEMP) and one sample of $1 \%$ TEMP aqueous solution were treated by avoiding light for $30 \mathrm{~min}, 470 \mathrm{~nm}$ laser irradiation for $5 \mathrm{~min}$, and 30 min respectively, and then transferred to quartz capillary for electron spin resonance (ESR) spectra measurement.

\section{Western blot analysis}

Cells were collected and lysed in strong RIPA buffer at $4{ }^{\circ} \mathrm{C}$ for $1 \mathrm{~h}$. Samples were subsequently centrifuged at $12,000 \mathrm{rpm}$ for $15 \mathrm{~min}$ at $4{ }^{\circ} \mathrm{C}$ and the supernatants were collected. The protein was quantified using Pierce BCA ProteinAssay (Thermo Scientific, USA, 23228). Protein was diluted in SDS-PAGE loading buffer (YEASEN, S8901110) and denatured at $95{ }^{\circ} \mathrm{C}$ for $10 \mathrm{~min}$. Equal amounts of samples were separated by $10-12 \%$ SDSPAGE and transferred onto PVDF membranes. After blocking with $5 \%$ non-fat milk for $1 \mathrm{~h}$ at room temperature, the membranes were incubated with the indicated antibodies (LC3B, 1:2000, SigmaL7543; Beclin1, 1:1000, CST4122; p62, 1:1000, CST88588; p53, 1:500, CST2524; AMPK, 1:1000, CST5831; pAMPK, 1:1000, CST2535; BAX, 1:1000, CST2772; Bcl-xL, 1:1000, CST2764; Caspase-3, 1:1000, CST14220; GAPDH, 1:1000, SC-47724; $\beta$-actin, 1:1000, SC-69879) overnight at $4{ }^{\circ} \mathrm{C}$. Membranes were washed with TBST three times and incubated in secondary antibodies (HRP-conjugated goat antimouse antibody, 1:3000, ab6789; HRP-conjugated goat anti-rabbit antibody, 1:3000, ab6721) for $1.5 \mathrm{~h}$ at room temperature. The blots were finally detected using an enhanced chemiluminescence system.

\section{mCherry-GFP-LC3 transient transfection}

For autophagic flux analysis, Huh7 cells with different treatment were infected with adenovirus expressing mCherry-GFP-LC3 fusion protein. After incubation in complete medium for $24 \mathrm{~h}$, cells were observed under a fluorescence microscope. Autophagic flux was assessed by manually counting the number of yellow and red dots of each cell in five random fields from the images that merged the red and green channels. Yellow and red dots represented autophagosomes and autolysosomes, respectively.

\section{Vivo experiment}

\section{Evaluation of vivo toxicity}

For the in vivo toxicity, BALB/nu male mice (6 weeks old) were purchased from Changzhou Cavens Laboratory Animal Company or C57BL/6J male mice (6 weeks old) were purchased from Hunan SJA Laboratory Animal Company. After 1 week acclimation, the mice were randomly divided into two groups and were treated with $300 \mu \mathrm{l}(750 \mu \mathrm{g}) \mathrm{TC}-\mathrm{WS}-\mathrm{CQDs}$ or $300 \mu \mathrm{l}$ PBS by tail vein injection every 2 days. Blood samples were collected for the toxicity-related parameters analysis and major organs were fixed with $4 \%$ paraformaldehyde for hematoxylineosin (HE) staining at day 14.

\section{Photodynamic therapy (PDT) in hepatocellular carcinoma bearing mice}

BALB/nu mice (5 weeks) were purchased from Changzhou Cavens Laboratory Animal Company. Following 1 week acclimation, hepatocellular carcinoma was established by subcutaneous injection of $2.5 \times 10^{6}$ of Huh7 cells suspended in $100 \mu \mathrm{l}$ of PBS into the nude mice. The mice were randomly divided into four groups with each 5 mice: CQDs $+\mathrm{I}_{470 \mathrm{~nm}}$ group (injection of TC-WS-CQDs through tail vein and $470 \mathrm{~nm}$ irradiation for $10 \mathrm{~min}$ ), CQDs group (injection of TC-WS-CQDs through tail vein), $\mathrm{I}_{470 \mathrm{~nm}}$ group (470 $\mathrm{nm}$ irradiation for $10 \mathrm{~min}$ ), PBS group (injection of PBS through tail vein). The mice were subjected to different treatment every 2 days when the tumor size reached 5-8 $\mathrm{mm}$. The body weight and the tumor size were monitored every 2 days.

\section{Immunohistochemistry}

The mice were sacrificed and tumors were extracted at day 10. Immunohistochemical detection was performed using the DAKO kit (K5007, Denmark) following the manufacturer's instructions. The primary antibody LC3 was 1:300 dilution (14600-1-AP, Proteintech), primary antibody p53 was 1:200 dilution (21891-1-AP, Proteintech), and primary antibody pAMPK was 1:100 dilution (CY6027, Abways). The secondary antibody was Goat-anti-Rabbit IgG (DAKO). After immunostaining, sections were counterstained with hematoxylin.

\section{Statistical analysis}

Statistical graphs were plotted by OriginPro 2021 software or GraphPad Prism 8.0.1 software. Statistical analysis was performed by SPSS 22.0 software. Data were represented as means $\pm S D$. Comparisons of data with a normal distribution between two groups were analyzed using unpaired $t$ tests or two-way ANOVA. Otherwise, comparisons were analyzed using nonparametric MannWhitney test. $p$ value less than 0.05 was considered statistically significant. ${ }^{* * * * *} \mathrm{p}<0.00011^{* * * *} \mathrm{p}<0.001{ }^{* * *} \mathrm{p}<0.01$, "p $<0.05$, ns: not significant. All experiments were performed at least in triplicate. 


\section{Results and discussion}

Synthesis and structural characterizations of TC-WS-CQDs TC-WS-CQDs were synthesized from an optimized proportion of tryptophan and sorbitol (100:500) in a one-pot hydrothermal method at $160{ }^{\circ} \mathrm{C}$. The results showed that tryptophan had an important influence on the optical characteristics of the TC-WS-CQDs, and the addition of sorbitol could significantly reduce the proportion of amorphous carbon dots. The reactant was centrifuged to remove the precipitate, and the silica gel column chromatography was performed with ethanol and ethyl acetate as the eluent. In the process of column chromatography, rainbow-colored bands, mainly blue, green, and red, could be observed (Additional file 1: Figure S1). The B-, G-, and R-WS-CQDs carbon quantum dots were collected sequentially by gradient elution. TEM images showed that the B-, G-, and R-WS-CQDs had similar sizes and shapes with an average diameter of $\approx 1.4 \mathrm{~nm}$
(Fig. 1A). High-resolution TEM (HRTEM) images showed that all three types of TC-WS-CQDs exhibit clear lattice fringes with a spacing of $0.21 \mathrm{~nm}$, which corresponds to the graphene (100) in-plane lattice, indicating that the difference in color of TC-WS-CQDs came from the surface and/or edges chemical composition rather than the size of the quantum dots (Fig. 1A inset). Compared with most of published synthetic methods of carbon dots, the synthesis of TC-WS-CQDs was simple, convenient and bio-friendly (Additional file 1: Table S1).

\section{Optical characterizations of TC-WS-CQDs}

The most significant optical feature of B-, G- and R-WSCQDs are continuous and different absorption and emission peaks. The fluorescence photoluminescence excitation-emission matrix (EEM) and the ultraviolet-visible (UV-Vis) absorption spectrum showed that




the B-, G-, and R-WS-CQDs had strong absorption at the center wavelengths of $300 \mathrm{~nm}, 457 \mathrm{~nm}$, and $540 \mathrm{~nm}$, respectively, and emit fluorescence at the maximum emission wavelengths of $453 \mathrm{~nm}, 506 \mathrm{~nm}$, and $581 \mathrm{~nm}$ (Fig. 1B), which allowed carbon quantum dots with different excitation wavelengths to be used separately in organisms.

\section{Chemical composition analysis}

In order to determine the mechanism of differences in optical properties of TC-WS-CQDs with the same size and crystal structure, fourier transform infrared (FTIR) spectroscopy and X-ray photoelectron spectroscopy (XPS) were used for chemical composition analysis. The FT-IR spectrum (Fig. 2A) showed characteristic absorption peaks at 3395, 3212, 1592, and $1362 \mathrm{~cm}^{-1}$ were assigned to the stretching vibrations of $\mathrm{O}-\mathrm{H}, \mathrm{N}-\mathrm{H}, \mathrm{C}=\mathrm{O}$ and $\mathrm{C}-\mathrm{O}$ of $\mathrm{B}-$, G- and R-WS-CQDs, suggesting that TCWS-CQDs had similar groups. Furthermore, high-resolution XPS verified the FT-IR conclusion and confirmed the proportion of the groups. As shown in Fig. 2B, with the red shift of the emission wavelength, the proportion of hydroxyl and amino groups gradually increased, and the R-WS-CQDs contained a high proportion of amide bonds and carboxyl groups. The G-WS-CQDs had a higher proportion of pyrrolic N, indicating that G-WSCQDs had a higher proportion of tryptophan residues.

\section{Cellular imaging and distribution of TC-WS-CQDs}

We detected the bioimaging of TC-WS-CQDs in Huh7 HCC cells. Using laser scanning confocal microscope (LSCM), B-, G-, and R-WS-CQDs generated blue, green, and red fluorescence respectively in Huh7 cells after incubation with TC-WS-CQDs for $6 \mathrm{~h}$ (Fig. 3A). To determine how TC-WS-CQDs entered Huh7 cells, we further monitored the endocytosis. After incubating with the endocytosis inhibitors (nystatin or chlorpromazine), the fluorescence intensity in Huh7 cells was decreased, indicating that the TC-WS-CQDs could enter cells by endocytosis (Fig. 3B). Additionally, TEM scanning revealed that intracellular localization of TC-WS-CQDs was mainly in the cytoplasm, and some were contained within intracytoplasmic vesicles including lysosome (Fig. 3C). LysoTracker Red further indicated most G-WSCQDs were co-localization with lysosomes (Fig. 3D). These results confirm this carbon nanomaterial contains
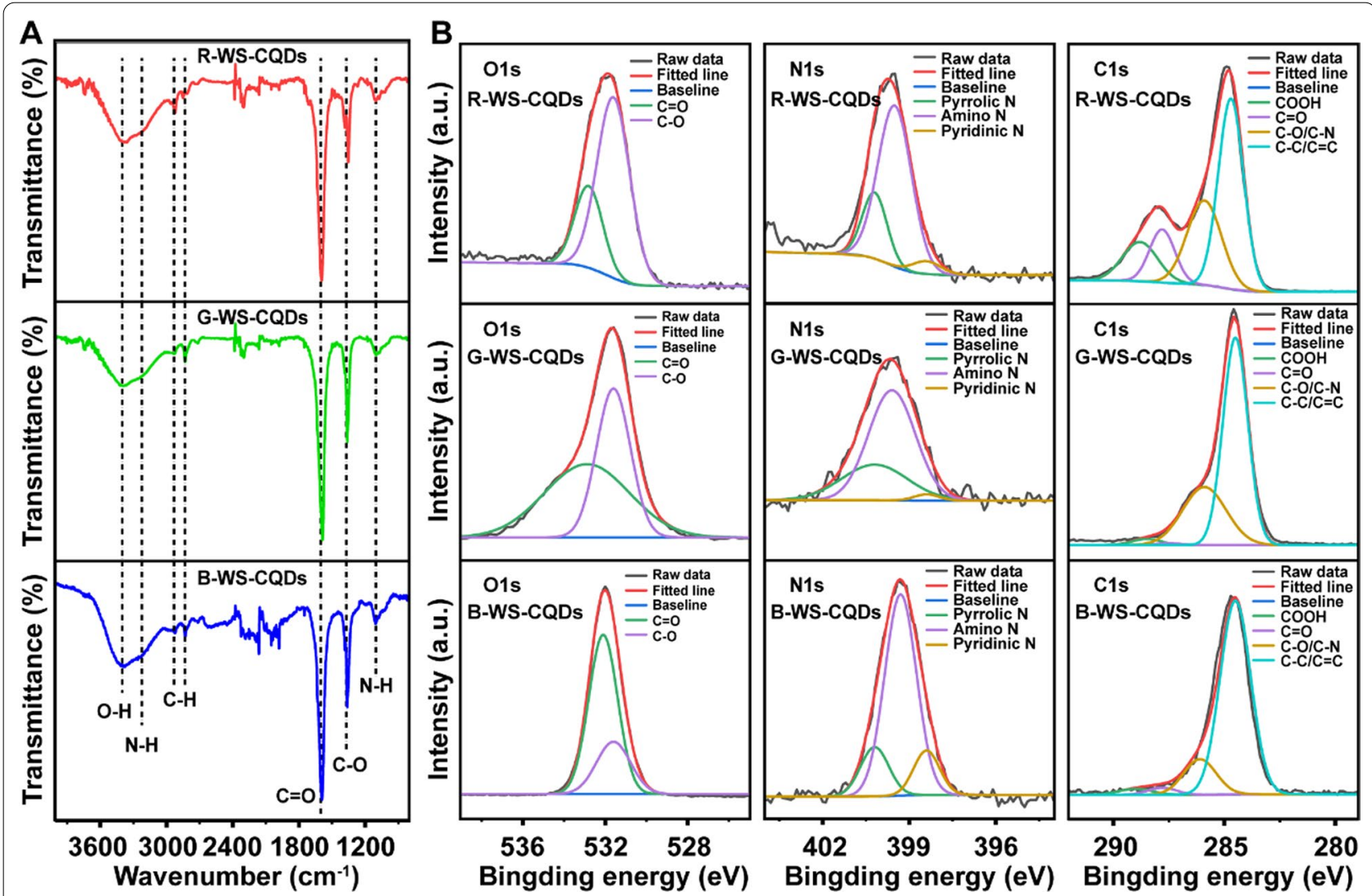

Fig. 2 A FT-IR spectrum of B-WS-CQDs, G-WS-CQDs, and R-WS-CQDs. B High resolution X-ray photoelectron spectroscopy (XPS) spectrum of TC-WS-CQDs for O1s (left), N1s (medium), C1s (right) 


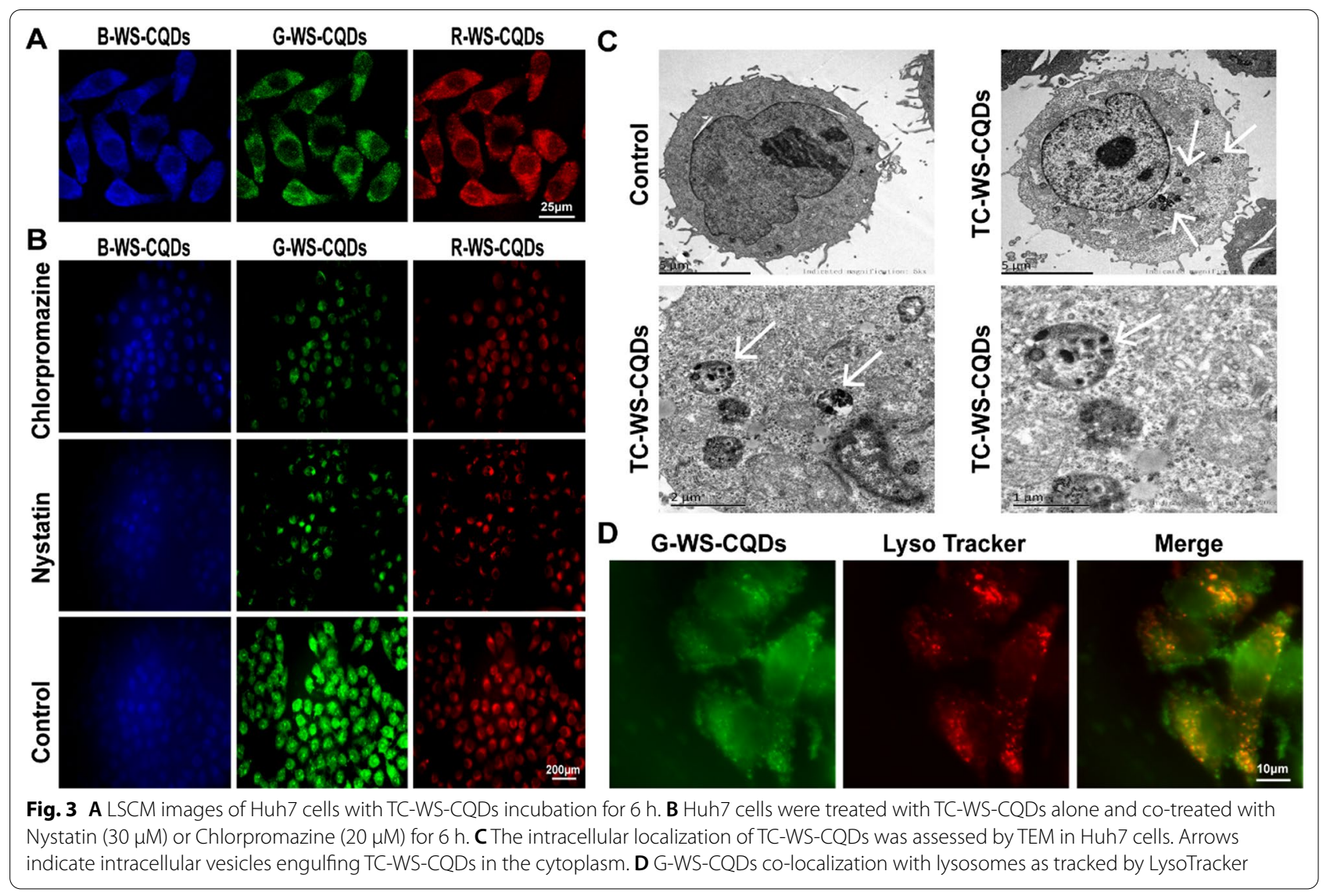

B-, G- and R-WS-CQDs and is mainly absorbed into lysosomes of the tumor cells in a proactive way.

In vivo distribution of TC-WS-CQDs, we quantified the fluorescence intensity of tissue homogenate using the microplate reader after injection of TC-WS-CQDs in C57BL/6J. As shown in Additional file 1: Figure S2, the fluorescence intensity was increased in the liver and in the kidney at $1 \mathrm{~h}$ after injection of TC-WS-CQDs, indicting TC-WS-CQDs could be enriched in the liver and kidney.

\section{Biotoxicity analysis of TC-WS-CQDs}

The cytotoxicity of TC-WS-CQDs in Huh7 cells and L02 cells were evaluated by CCK8 and MTS assay. TC-WSCQDs did not suppress Huh7 cells survival in a dose and time-dependent way until its concentration was up to $200 \mu \mathrm{g} / \mathrm{ml}$ (Fig. 4A and C), which was a higher concentration than that was needed for application. TC-WS-CQDs exhibited less toxicity in L02 cells (Fig. 4B and D). Meanwhile, TC-WS-CQDs had no obvious toxicity in BALB/ nu mice mice after injecting TC-WS-CQDs for 14 days. As shown in Fig. 4E, TC-WS-CQDs did not cause abnormal serum index. Consistent with the serological test results, HE staining revealed no injury of organs after injecting TC-WS-CQDs (Fig. 4F). No toxicity was observed in C57BL/6J mice (Additional file 1: Figure S3).

For many years, semiconductor quantum dots are used as biosensors in medical studies, because of excellent fluorescence emission. However, their remarkable toxicity induced by heavy metals limits safe use for clinical applications [26]. Based on these results, TC-WSCQDs have excellent biocompatibility with minimal toxicity, showing a promising nanomaterial for medical applications.

\section{TC-WS-CQDs selectively targeting hepatoma cells}

To investigate the selectivity of TC-WS-CQDs towards hepatoma cells, Huh7 cells and L02 cells were incubated with TC-WS-CQDs $(200 \mu \mathrm{g} / \mathrm{ml})$ separately. Blue and red fluorescence between Huh7 cells and L02 cells were not obviously different. However, upon incubation with TC-WS-CQDs for $4 \mathrm{~h}$, Huh7 cells showed bright green fluorescence at $470 \mathrm{~nm}$ excitation, while non-cancerous L02 cells appeared relatively faint green fluorescence (Additional file 1: Figure S4A). Over $6 \mathrm{~h}$ incubation with TC-WS-CQDs, the green fluorescence intensity of Huh7 cells enhanced rapidly and had 



Fig. 4 The biocompatibility of TC-WS-CQDs. A-D Cell viability of Huh7 cells and L02 cells, CCK8 assay (A, B), MTS assay (C, D). Cells were seeded to 96 -well plates $\left(8 \times 10^{3}\right.$ cells/well). E, F Toxicity assessment of TC-WS-CQDs in BALB/nu mice $(n=5)$. The mice were intravenously injected with TC-WS-CQDs or PBS (300 $\mu \mathrm{ll}$ ) every 2 days. The blood and organs were collected at day 14, E Complete blood count test and serum biochemistry results. F Histological evaluation of the major organs of the mice. WBC white blood cells, PLT platelet, RBC red blood cells, Hb hemoglobin, TBIL total bilirubin, ALT alanine aminotransferase, ALP alkaline phosphatase, Scr serum creatinine, LDH lactate dehydrogenase. Data represent mean \pm SD ( $n=3$ in $\mathbf{A}-\mathbf{D}, n=5$ in $\mathbf{E}, \mathbf{F}$, Mann-Whitney test or unpaired t test were used when appropriate for statistical significance analysis in $\mathbf{E}$. ns: not significant)

significant differences compared with that of L02 cells (Additional file 1: Figure S4B-D). It is expected that the tumor cells might prefer to swallow G-WS-CQDs compared with normal hepatocytes, which implies a tumor targeting characteristics of the TC-WS-CQDs.
TC-WS-CQDs for photodynamic therapy in vitro

To detect the potential efficiency of TC-WS-CQDs for PDT, we assessed the proliferation of Huh7 cells using the TC-WS-CQDs irradiated for $10 \mathrm{~min}$ with different wavelengths. The cells died upon irradiation at $365 \mathrm{~nm}$ without TC-WS-CQDs (Additional file 1: Figure S5A). 


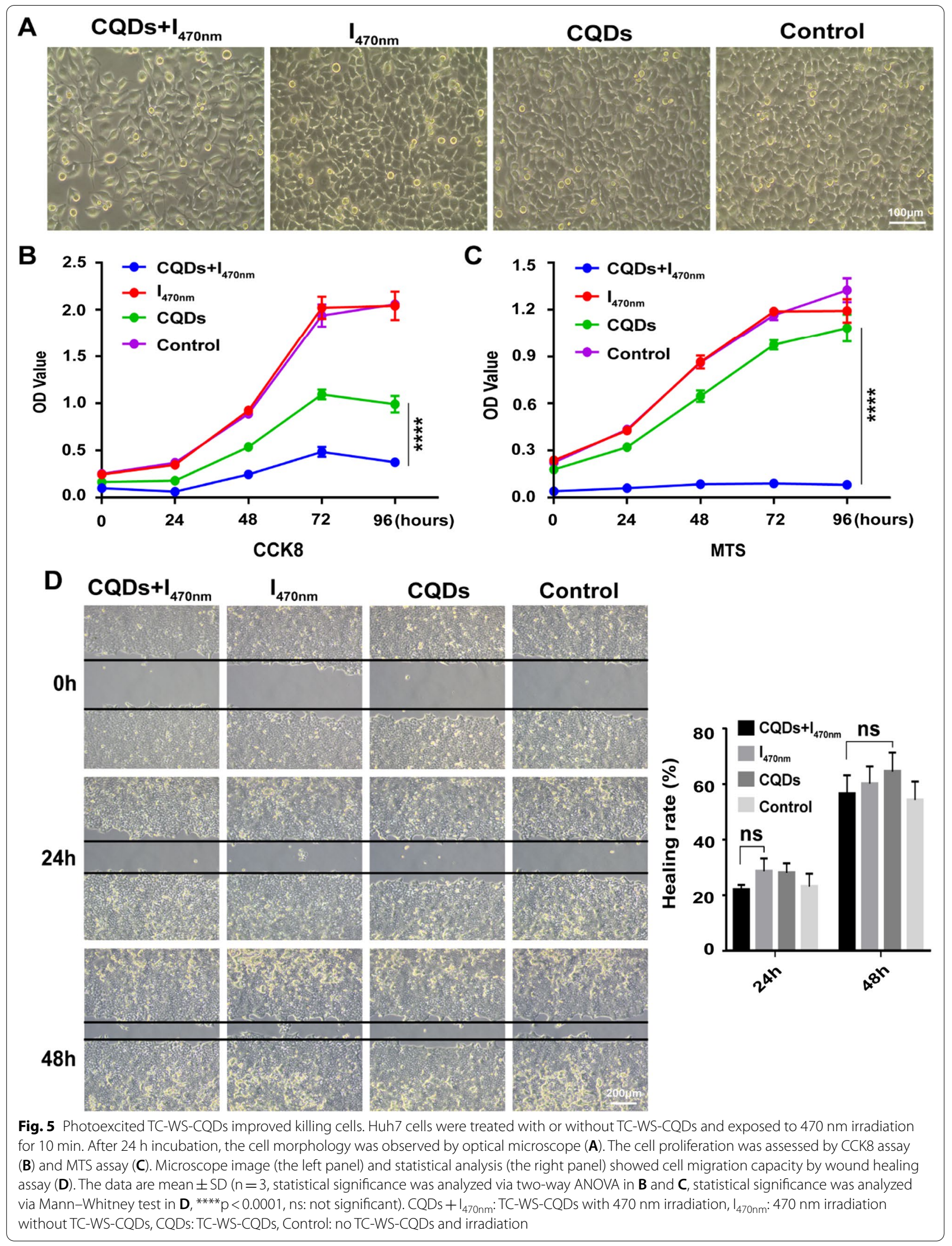




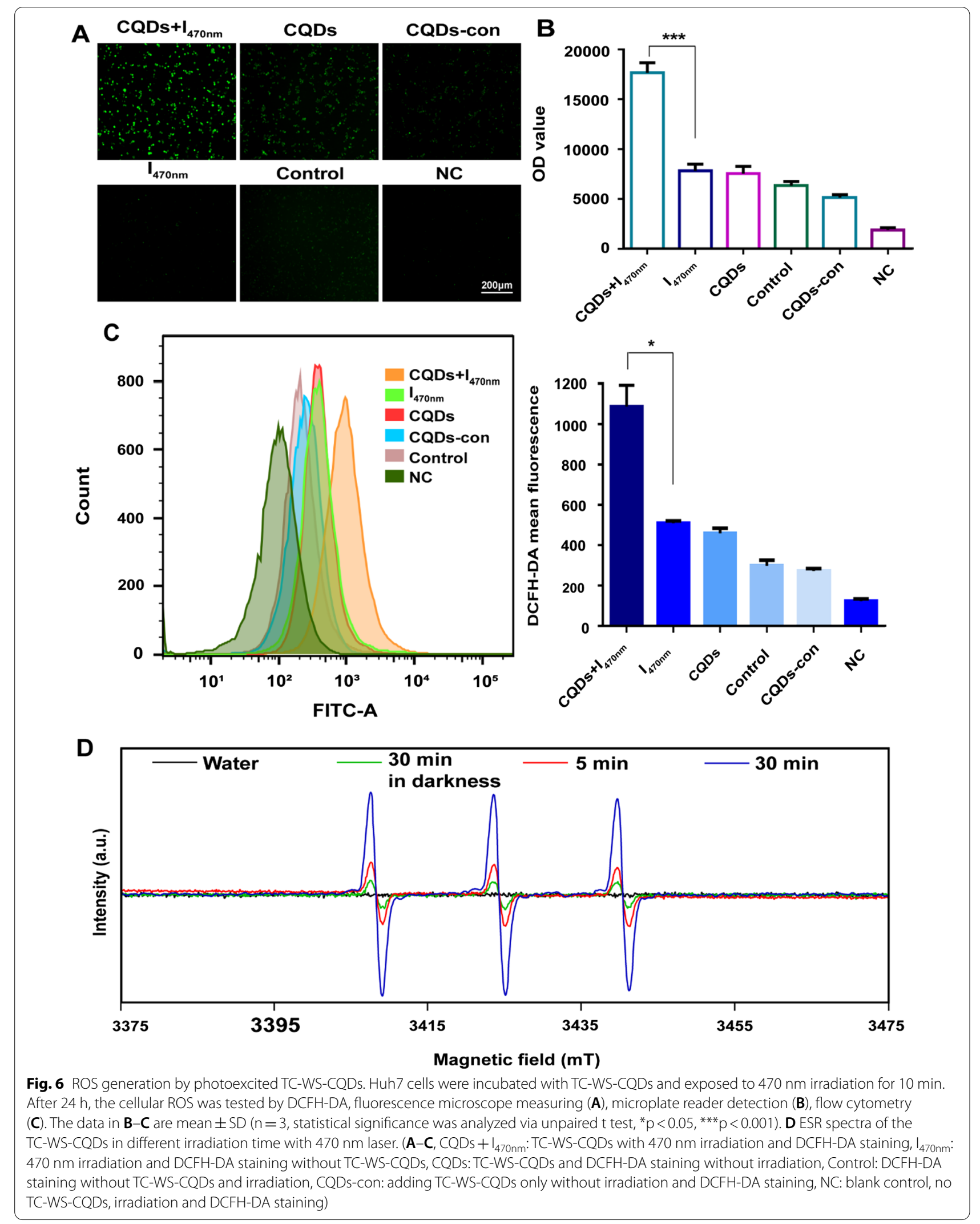




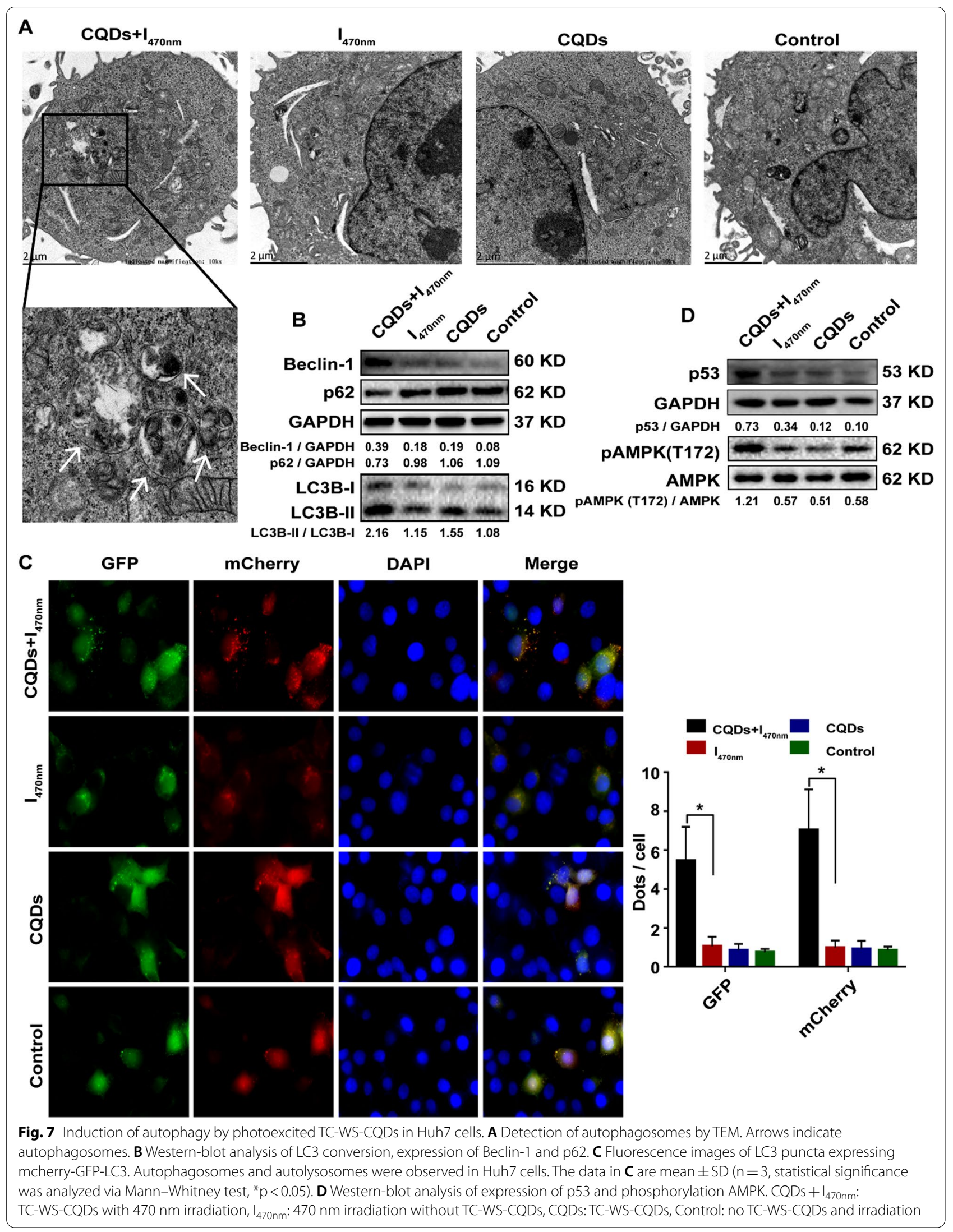


In addition, TC-WS-CQDs with irradiation at $545 \mathrm{~nm}$ had no effects on proliferation of Huh7 cells (Additional file 1: Figure S5B, C). However, Huh7 cells were inhibited significantly upon irradiation at $470 \mathrm{~nm}$ (Fig. 5AC), but no effects on cell migration were observed (Fig. 5D). These results indicated $470 \mathrm{~nm}$ photoexcited TC-WS-CQDs in PDT for hepatocellular carcinoma at the cellular level.

\section{TC-WS-CQDs activating autophagy via producing ROS}

Considering photodynamic cytotoxicity of TC-WSCQDs with $470 \mathrm{~nm}$ irradiation, we detected the intracellular ROS levels in Huh7 cells via DCFH-DA after incubation with TC-WS-CQDs. Consistent with our previous result of PDT in Huh7 cells, TC-WS-CQDs irradiation at $545 \mathrm{~nm}$ did not induce intracellular ROS generation (Additional file 1: Figure S6A-C). However, fluorescence imaging showed increasing ROS in Huh7 cells with the TC-WS-CQDs under irradiation at $470 \mathrm{~nm}$ (Fig. 6A). Quantitative analysis with microplate reader or flow cytometry also displayed a significant increase in intracellular ROS production of $470 \mathrm{~nm}$ irradiated TCWS-CQDs (Fig. 6B and C). Moreover, the ROS inhibitors (NAC and APO) didn't decrease ROS level (Additional file 1: Figure S7A, B), thus indicating that ROS sources were not mitochondrial-derived ROS and NADPH oxidase-induced ROS. Additionally, the ${ }^{1} \mathrm{O}_{2}$-generation capability of the TC-WS-CQDs was investigated by ESR technique (Fig. 6D) with TEMP as an ${ }^{1} \mathrm{O}_{2}$ trapper. These results proved that the ROS was exogenous, which generated from TC-WS-CQDs with $470 \mathrm{~nm}$ irradiation.

As shown in Fig. 3C and D, lots of the TC-WS-CQDs entered lysosomes in tumor cells, which may represent occurrence of autophagy caused by ROS [27]. Given that TC-WS-CQDs generated ROS upon photoexcitation at $470 \mathrm{~nm}$, we further assessed whether TC-WS-CQDs caused autophagy in tumor cells. TEM analysis showed the generation of autophagosomes in $470 \mathrm{~nm}$-irradiated TC-WS-CQDs group (Fig. 7A). Immunoblot assay revealed the conversion of LC3BI to LC3B-II, upgradation of Beclin-1 and degradation of p62 under $470 \mathrm{~nm}$-irradiated TC-WS-CQDs, which indicated the formation of autophagosomes and autolysosomes (Fig. 7B). mCherry-GFP-LC3 fluorescence microscope assay confirmed the increasing numbers of autophagosomes and autolysosomes by $470 \mathrm{~nm}$-irradiated TC-WS-CQDs (Fig. 7C). Additionally, flow cytometry also indicated a larger LC3B signal in $470 \mathrm{~nm}$ irradiated TC-WS-CQDs group (Additional file 1: Figure S8). Besides, immunoblot assay showed that p53 and pAMPK upgraded in $470 \mathrm{~nm}$-irradiated TC-WS-CQDs group (Fig. 7D), indicating p53 signaling as a mediator of the autophagic pathway in Huh7 cells. However, apoptotic parameters had no significant changes in Huh7 cells with $470 \mathrm{~nm}$-irradiated and non-irradiated TC-WSCQDs (Additional file 1: Figure S9).

\section{TC-WS-CQDs for photodynamic therapy in vivo}

To address whether the TC-WS-CQDs exerted potential therapeutic role against $\mathrm{HCC}$ in vivo, we next performed animal PDT experiments. Mice were intratumorally injected with PBS or TC-WS-CQDs, and the tumor site was subjected to $470 \mathrm{~nm}$ irradiation or no irradiation. The body weight of mice and the tumor volume were measured every 2 days. After the treatment for 10 days, all mice were sacrificed and the tumors were excised and weighed. The results showed that the tumor size was the smallest in CQDs $+\mathrm{I}_{470 \mathrm{~nm}}$ group (Fig. 8A). Both the tumor volume and the tumor weight in CQDs $+\mathrm{I}_{470 \mathrm{~nm}}$ group had significant differences compared with other groups (Fig. 8B and C). Meanwhile, the body weight had no significant difference between the four groups during the experiment (Fig. 8D). Immunohistochemistry revealed LC3, p53 and pAMPK were high expression in CQDs $+\mathrm{I}_{470 \mathrm{~nm}}$ group (Fig. 8E). Collectively, PDT of TCWS-CQDs for HCC was further validated in vivo.

Currently, sorafenib and lenvatinib are the first-line approved agents in HCC [28, 29]. Although sorafenib can prolong survival in HCC patients, the response rate is usually low and its efficacy is short owing to the development of resistance $[28,30]$. In addition, traditional chemotherapeutic drugs often cause systemic toxicity because they are not well-targeted to the tumors. TC-WS-CQDs, targeting to HCC cells, showed an effective anti-HCC efficacy without toxicity. Herein, we demonstrated a novel strategy for HCC treatment with no systemic toxicities compared to the popular chemotherapeutic drugs.

(See figure on next page.)

Fig. 8 In vivo PDT of TC-WS-CQDs. A Photos of the excised tumors on day 10 (X: failed to form tumor). B The tumor volume of mice as a function of time. C Quantitative analysis of tumor weight on day 10. D Body weight of Huh7 cancer bearing mice of different groups after treatments. $\mathbf{E}$ The detection of LC3, p53 and pAMPK expression in tumors by immunohistochemistry. The data are mean \pm SD $(n=5$, statistical significance was analyzed via two-way ANOVA in B, statistical significance was analyzed via unpaired t test in $\mathbf{C},{ }^{*} p<0.05,{ }^{* *} p<0.01$, ns: not significant. CQDs $+I_{470 n m:}$ TC-WS-CQDs with $470 \mathrm{~nm}$ irradiation, $1_{470 \mathrm{~nm}}: 470 \mathrm{~nm}$ irradiation without TC-WS-CQDs, CQDs: TC-WS-CQDs, PBS: no TC-WS-CQDs and irradiation 


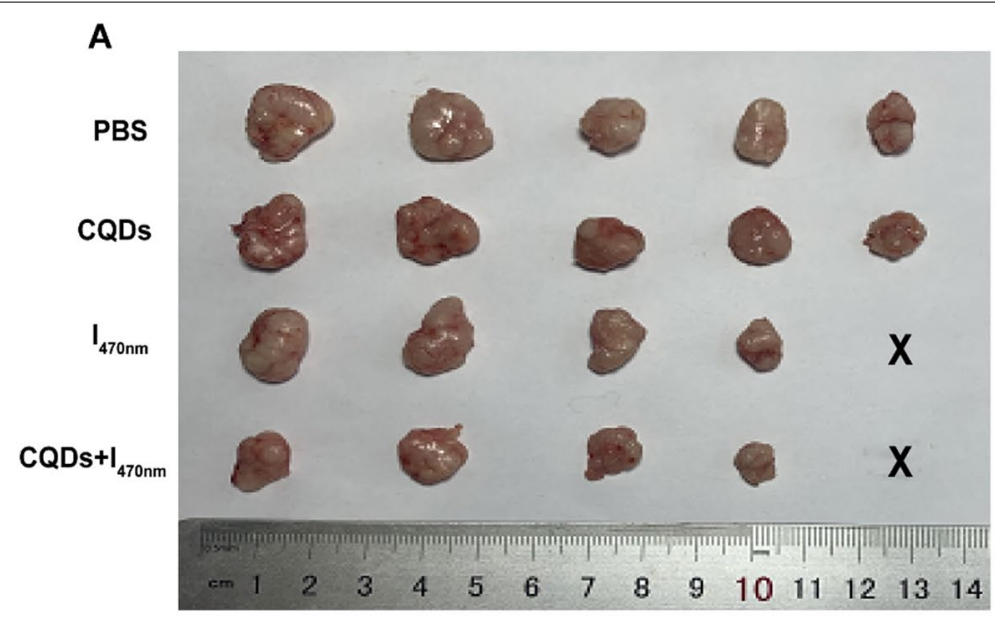

B

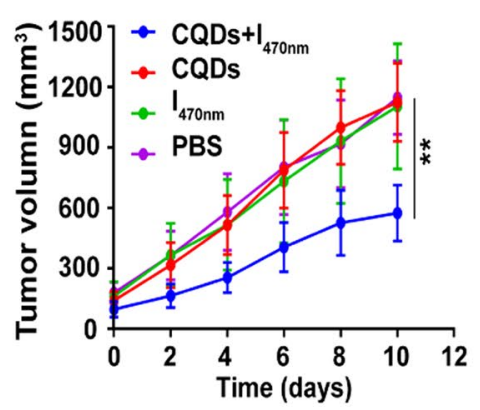

C

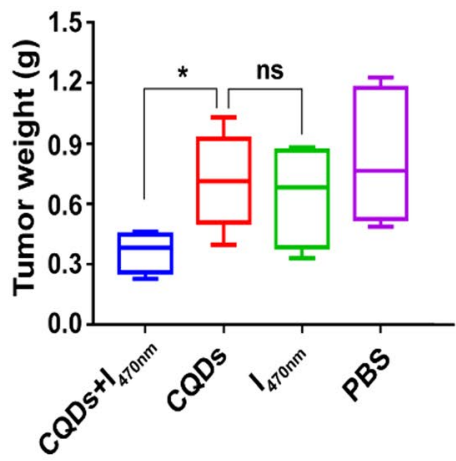

CQDs

$\mathrm{I}_{470 \mathrm{~mm}}$

D

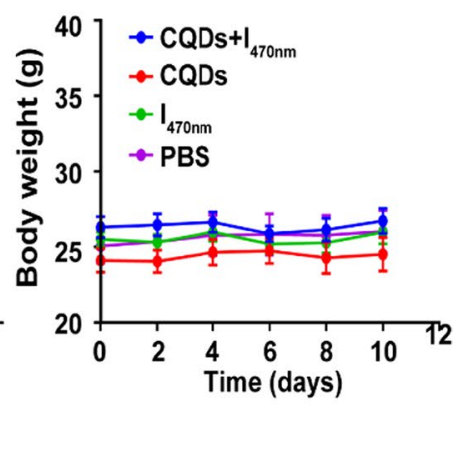

E CQDs+1 ${ }_{470 \mathrm{~m}}$



PBS

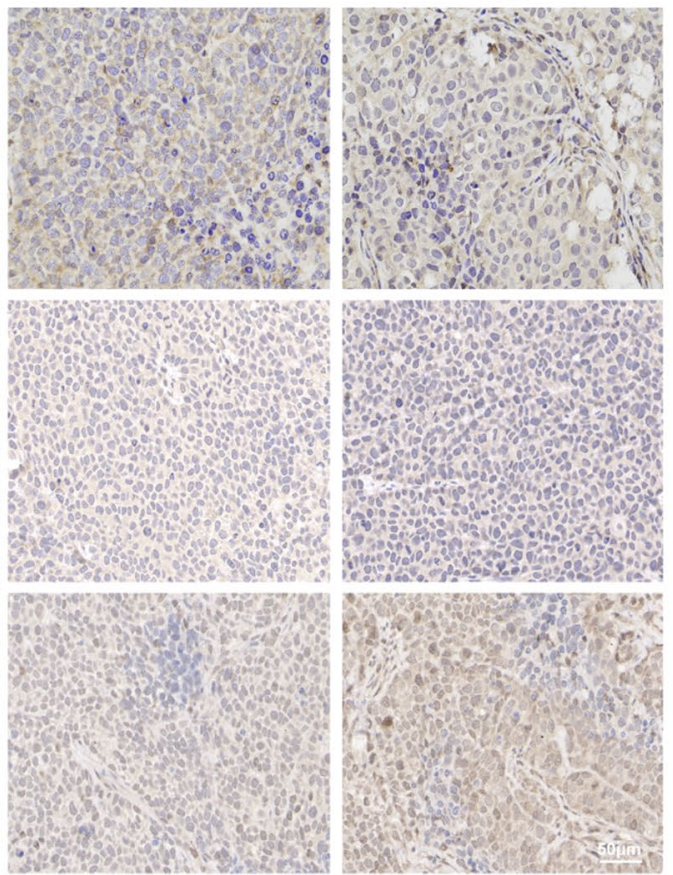

PAMPK

Fig. 8 (See legend on previous page.) 


\section{Conclusions}

In summary, we have developed a theranostic nanoplatform of TC-WS-CQDs via environmental-friendly hydrothermal decomposition of tryptophan and sorbitol for $\mathrm{HCC}$ treatment. In contrast to normal hepatocyte, higher targeting into HCC cells by the TC-WS-CQDs may lead to early monitoring of tumor cells through fluorescence imaging. Simultaneously, the green-emitting TC-WS-CQDs enhance HCC prevention in vitro and in vivo without any drug-delivery. This anticancer therapy is due to ROS generation activating autophagy via p53-AMPK pathway. This study may highlight a promising anticancer nanotheranostic strategy with integration of diagnosis, targeting, and therapy.

\begin{abstract}
Abbreviations
HCC: Hepatocellular carcinoma; PD-1: Programmed cell death protein 1; PDL1: Programmed cell death-ligand protein 1; CQDs: Carbon quantum dots; PL: Photoluminescence; TC-WS-CQDs: Trichrome-tryptophan-sorbitol CQDs; ROS: Reactive oxygen species; DMEM: Dulbecco's Modified Eagle's Medium; RPMI: Roswell Park Memorial Institute; FBS: Fetal bovine serum; CCK8: Cell Counting Kit-8; MTS: 3-(4,5-Dimethylthiazol-2-yl)-5-(3-carboxymethoxyphenyl)-2-(4sulfophenyl)-2H-tetrazolium, inner salt; PBS: Phosphate-buffered saline; NAC: $\mathrm{N}$-Acetylcysteine; APO: Apocynin; ${ }^{1} \mathrm{O}_{2}$ : Singlet oxygen; OD: Optical density; DCFH-DA: 2',7'-Dichlorodi-hydrofluorescein diacetate dye; TEMP: 2,2,6,6-Tetramethylpiperidine; ESR: Electron spin resonance; HE: Hematoxylin-eosin; PDT: Photodynamic therapy; TEM: Transmission electron microscopy; HRTEM: Highresolution TEM; EEM: Excitation-emission matrix; UV-Vis: Ultraviolet-visible; FT-IR: Fourier transform infrared; XPS: X-ray photoelectron spectroscopy; LSCM: Laser scanning confocal microscope; WBC: White blood cells; PLT: Platelet; RBC: Red blood cells; Hb: Hemoglobin; TBIL: Total bilirubin; ALT: Alanine aminotransferase; ALP: Alkaline phosphatase; Scr: Serum creatinine; LDH: Lactate dehydrogenase.
\end{abstract}

\section{Supplementary Information}

The online version contains supplementary material available at https://doi. org/10.1186/s12951-022-01275-2.

Additional file 1. Supplementary table and figures

\section{Acknowledgements}

Not applicable.

\section{Authors' contributions}

WY, LN, GMM, and FXG designed the study and supervised the project. TJK and WGC synthesized the nanomaterials and analyzed the characterization. CJ performed the cell and animal experiment. TJK and CJ analyzed data. LWK drew the schematic diagram. WY, CJ, and TJK wrote the manuscript. HZB, LN, GMM, and FXG reviewed and edited the manuscript. All authors read and approved the final manuscript.

\section{Funding}

This work was supported by Hunan Provincial Natural Science Foundation of China (No. 2019JJ30042), Innovation-Driven Project of Central South University (No. 2020CX047), Science and Technology Innovation Program of Hunan Province (No. 2021RC3030), Fundamental Research Funds for the Central Universities: Southwest University (No. 5330500110).

\section{Availability of data and materials}

All data generated or analyzed during this study are included in this published article and its additional information files.

\section{Declarations}

\section{Ethics approval and consent to participate}

Animal experiments were approved by the Ethical Committee of Xiangya Hospital, Central South University in compliance with the law on experimental animals and the Ethical approval number is 201603112.

\section{Consent for publication}

Not applicable.

\section{Competing interests}

The authors declare that they have no competing interests.

\section{Author details}

${ }^{1}$ Key Laboratory of Viral Hepatitis of Hunan Province, Xiangya Hospital, Central South University, Xiangya Road 87, Kaifu District, Changsha 410008, China. ${ }^{2}$ Institute of Integrative Medicine, Department of Integrated Traditional Chinese and Western Medicine, Xiangya Hospital, Central South University, Changsha 410008, China. ${ }^{3}$ National Clinical Research Center for Geriatric Disorders, Xiangya Hospital, Central South University, Changsha 410008, China ${ }^{4}$ Department of Infectious Diseases, Xiangya Hospital, Central South University, Changsha 410008, China. ${ }^{5}$ School of Chemistry and Chemical Engineering, Southwest University, Tiansheng Road, Beibei District, Chongqing 400715, China. ${ }^{6}$ Department of Blood Transfusion, Xiangya Hospital, Central South University, Changsha 410008, China.

Received: 20 October 2021 Accepted: 20 January 2022

Published online: 14 February 2022

\section{References:}

1. Sung H, Ferlay J, Siegel RL, Laversanne M, Soerjomataram I, Jemal A, Bray F. Global cancer statistics 2020: GLOBOCAN estimates of incidence and mortality worldwide for 36 cancers in 185 countries. CA Cancer J Clin. 2021;71:209.

2. Fernández Varo G, Perramón M, Carvajal S, Oró D, Casals E, Boix L, Oller L, Macías Muñoz L, Marfà S, Casals G, Morales Ruiz M, Casado P, Cutillas PR, Bruix J, Navasa M, Fuster J, Garcia Valdecasas JC, Pavel MC, Puntes V, Jiménez W. Bespoken nanoceria: an effective treatment in experimental hepatocellular carcinoma. Hepatology. 2020;72:1267.

3. Ren Z, Chen X, Hong L, Zhao X, Cui G, Li A, Liu Y, Zhou L, Sun R, Shen S, Li J, Lou J, Zhou H, Wang J, Xu G, Yu Z, Song Y, Chen X. Nanoparticle conjugation of ginsenoside Rg3 inhibits hepatocellular carcinoma development and metastasis. Small. 2019;16:1905233.

4. Yang JD, Heimbach JK. New advances in the diagnosis and management of hepatocellular carcinoma. BMJ. 2020;371:m3544

5. Forner A, Reig M, Bruix J. Hepatocellular carcinoma. Lancet. 2018;391:1301.

6. Cheng A, Hsu C, Chan SL, Choo S, Kudo M. Challenges of combination therapy with immune checkpoint inhibitors for hepatocellular carcinoma. J Hepatol. 2020;72:307.

7. Ryu JH, Lee S, Son S, Kim SH, Leary JF, Choi K, Kwon IC. Theranostic nanoparticles for future personalized medicine. J Control Release. 2014;190:477

8. Li X, Kim J, Yoon J, Chen X. Cancer-associated, stimuli-driven, turn on theranostics for multimodality imaging and therapy. Adv Mater. 2017;29:1606857.

9. Du J, Xu N, Fan J, Sun W, Peng X. Carbon dots for in vivo bioimaging and theranostics. Small. 2019;15:1805087.

10. Huang H, Lovell JF. Advanced functional nanomaterials for theranostics. Adv Funct Mater. 2017;27:1603524.

11. Abdelhamid HN, Talib A, Wu HF. One pot synthesis of gold - carbon dots nanocomposite and its application for cytosensing of metals for cancer cells. Talanta. 2017;166:357.

12. Wu Y, Deng P, Tian Y, Feng J, Xiao J, Li J, Liu J, Li G, He Q. Simultaneous and sensitive determination of ascorbic acid, dopamine and uric acid via an electrochemical sensor based on PVP-graphene composite. J Nanobiotechnol. 2020;18:112. 
13. Li G, Zhong P, Ye Y, Wan X, Cai Z, Yang S, Xia Y, Li Q, Liu J, He Q. A highly sensitive and stable dopamine sensor using shuttle-like a-Fe2O3 nanoparticles/electro-reduced graphene oxide composites. J Electrochem Soc. 2019;166:B1552.

14. Usmani A, Mishra A, Ahmad M. Nanomedicines: a theranostic approach for hepatocellular carcinoma. Artif Cells Nanomed Biotechnol. 2018:46:680.

15. Xu Q, Wan J, Bie N, Song X, Yang X, Yong T, Zhao Y, Yang X, Gan L. A biomimetic gold nanocages-based nanoplatform for efficient tumor ablation and reduced inflammation. Theranostics. 2018;8:5362.

16. Shen J, Kim H, Wolfram J, Mu C, Zhang W, Liu H, Xie Y, Mai J, Zhang H, Li Z, Guevara M, Mao Z, Shen H. A liposome encapsulated ruthenium polypyridine complex as a theranostic platform for triple-negative breast cancer. Nano Lett. 2017;17:2913.

17. Ji D, Ménard-Moyon C, Bianco A. Physically-triggered nanosystems based on two-dimensional materials for cancer theranostics. Adv Drug Deliv Rev. 2019;138:211.

18. Li Y, Shi N, Zhang W, Zhang H, Song Y, Zhu W, Feng X. Supramolecular hybrids of carbon dots and dihydroartemisinin for enhanced anticancer activity and mechanism analysis. J Mater Chem B. 2020:8:9777.

19. Ge J, Jia Q, Liu W, Guo L, Liu Q, Lan M, Zhang H, Meng X, Wang P. Red-emissive carbon dots for fluorescent, photoacoustic, and thermal theranostics in living mice. Adv Mater. 2015;27:4169.

20. Kong B, Zhu A, Ding C, Zhao X, Li B, Tian Y. Carbon dot-based inorganicorganic nanosystem for two-photon imaging and biosensing of $\mathrm{pH}$ variation in living cells and tissues. Adv Mater. 2012;24:5844.

21. Zulfajri M, Abdelhamid HN, Sudewi S, Dayalan S, Rasool A, Habib A, Huang GG. Plant part-derived carbon dots for biosensing. Biosensors. 2020;10:68.

22. Zheng M, Ruan S, Liu S, Sun T, Qu D, Zhao H, Xie Z, Gao H, Jing X, Sun Z. Self-targeting fluorescent carbon dots for diagnosis of brain cancer cells. ACS Nano. 2015;9:11455.

23. Li S, Su W, Wu H, Yuan T, Yuan C, Liu J, Deng G, Gao X, Chen Z, Bao Y, Yuan F, Zhou S, Tan H, Li Y, Li X, Fan L, Zhu J, Chen AT, Liu F, Zhou Y. Targeted tumour theranostics in mice via carbon quantum dots structurally mimicking large amino acids. Nat Biomed Eng. 2020;4:704.

24. Nocito G, Calabrese G, Forte S, Petralia S, Puglisi C, Campolo M, Esposito E, Conoci S. Carbon dots as promising tools for cancer diagnosis and therapy. Cancers. 2021;13:1991.

25. Liu Y, Yu N, Fang W, Tan Q, Ji R, Yang L, Wei S, Zhang X, Miao A. Photodegradation of carbon dots cause cytotoxicity. Nat Commun. 2021;12:812.

26. Nekoueian K, Amiri M, Sillanpaa M, Marken F, Boukherroub R, Szunerits S. Carbon-based quantum particles: an electroanalytical and biomedical perspective. Chem Soc Rev. 2019;48:4281.

27. Guo L, He N, Zhao Y, Liu T, Deng Y. Autophagy modulated by inorganic nanomaterials. Theranostics. 2020;10:3206.

28. Llovet JM, Ricci S, Mazzaferro V, Hilgard P, Gane E, Blanc J, de Oliveira AC, Santoro A, Raoul J, Forner A, Schwartz M, Porta C, Zeuzem S, Bolondi L, Greten TF, Galle PR, Seitz J, Borbath I, Häussinger D, Giannaris T. Sorafenib in advanced hepatocellular carcinoma. N Engl J Med. 2008;359:378.

29. Kudo M, Finn RS, Qin S, Han K, Ikeda K, Piscaglia F, Baron A, Park J, Han G, Jassem J, Blanc JF, Vogel A, Komov D, Evans TRJ, Lopez C, Dutcus C, Guo M, Saito K, Kraljevic S, Tamai T. Lenvatinib versus sorafenib in first-line treatment of patients with unresectable hepatocellular carcinoma: a randomised phase 3 non-inferiority trial. Lancet. 2018;391:1163.

30. Cheng A, Kang Y, Chen Z, Tsao C, Qin S, Kim JS, Luo R, Feng J, Ye S, Yang T, Xu J, Sun Y, Liang H, Liu J, Wang J, Tak WY, Pan H, Burock K, Zou J, Voliotis D. Efficacy and safety of sorafenib in patients in the Asia-Pacific region with advanced hepatocellular carcinoma: a phase III randomised, doubleblind, placebo-controlled trial. Lancet Oncol. 2009;10:25.

\section{Publisher's Note}

Springer Nature remains neutral with regard to jurisdictional claims in published maps and institutional affiliations. 